\title{
Ensinando matemática através dos códigos de barras
} Teaching Math through of the barcode

\author{
Cássia Regina dos Santos Takahashi ${ }^{* 1}$ \\ ${ }^{1}$ Mestre em Matemática, UNESP, São José do Rio Preto, Brasil
}

\begin{abstract}
Resumo
Este trabalho apresenta uma proposta de situação de aprendizagem de Matemática, contemplando o tema "código de barras", composta por cinco atividades, em que discutimos as orientações didáticas relativas a conceitos e procedimentos matemáticos e uso das tecnologias e analisamos os obstáculos que podem surgir durante o seu desenvolvimento. Justificamos essa proposta baseado nos documentos orientadores curriculares, que afirmam que o ensino de Matemática pode contribuir para a formação de um cidadão autônomo e crítico, através do desenvolvimento de metodologias que enfatizem a construção de estratégias para a solução de problemas reais, a comprovação e justificativa dos resultados encontrados, valorizando a criatividade, o interesse, a capacidade de abstrair o contexto, de generalizar, o trabalho coletivo e a autonomia advinda da confiança na própria capacidade para enfrentar desafios. Para esta finalidade, apresentamos inicialmente uma concepção do ensino de Matemática relacionado a essas metas. Em seguida apresentamos um breve histórico sobre os códigos de barras: surgimento, finalidade, evolução, importância e expansão no atual mundo globalizado e automatizado. Por fim, propomos a situação de aprendizagem analisando as possíveis estratégias de execução das atividades. Entendemos que tal situação de aprendizagem pode proporcionar um ambiente investigativo e criativo em sala de aula, potencializando a conexão entre os conceitos matemáticos envolvidos no tema com a aplicação em uma situação real, além de proporcionar uma maior participação do aluno nas aulas desta disciplina e de desenvolver o espírito crítico e inovador, melhorando a interação professor/aluno dentro de um ambiente de aprendizagem mútua.
\end{abstract}

Palavras-chave: Ensino de matemática. Situação de aprendizagem. Código de barras

\begin{abstract}
This work proposes a learning situation Mathematics, contemplating the theme "barcode", composed of five activities, we discussed the guidelines for the teaching concepts and mathematical procedures and use of technologies and analyze the obstacles that can arise during their development. We justify this proposal based on the guiding curriculum documents, claiming the teaching of mathematics can contribute to the formation of a national autonomous and critical, by developing methodologies that emphasize the development of strategies for solving real problems, evidence and justification the results, valuing creativity, interest, ability to abstract the context of widespread, collective work and autonomy arising from the confidence in one's ability to face challenges. For this purpose, we present an initial design of the teaching of mathematics related to these goals. Then we present a brief history of bar codes: appearance, purpose, evolution, importance and expansion in the current globalized world automated. Finally, we propose a learning situation and review possible strategies for implementation of activities. We understand that such a situation can provide a learning environment investigative and creative in the classroom , enhancing the connection between mathematical concepts involved in the subject of the application in a real situation, and provide greater student participation in lessons and this discipline develop critical thinking and innovative, improving teacher / student interaction within an environment of mutual learning .
\end{abstract}

Keywords: Mathematics teaching. Learning situation. Barcode 


\section{Introdução}

Diante das dificuldades relacionadas à aprendizagem de conceitos fundamen-tais de Matemática que muitos estudan-tes encontram, que acabam inclusive por desmo-tivá-los aos estudos, há uma necessidade de se investir na busca de novas formas de aprimorar as atividades de ensino. Nessa direção, os recur-sos de ensino constituídos por novas tecnologi-as, como a internet, os jogos digitais e os softwa-res educativos, tem se apresentado como pro-missores para facilitar e incentivar a participa-ção ativa dos alunos nas aulas.

Neste trabalho, apresentamos e discutimos uma proposta de Situação de Aprendizagem Matemática caracterizada pela meta de envolver os alunos em um processo de produção de um código de barras fictício. Tal situação de aprendizagem pode ser adaptada para várias séries, mas especialmente foi planejada a estudantes cursando a $7^{\text {a }}$ Série/8 $8^{\text {o }}$ Ano do Ensino Fundamental, pois o tema proposto está inserido na grade curricular da referida seriação no Sistema Estadual de Ensino de São Paulo.

A escolha desse tema de estudo baseia-se em dois aspectos: 1) compreender que o código de barras é produzido com base em conhecimentos matemáticos e, a partir disso, identificar as semelhanças e diferenças entre os códigos presentes nos diferentes produtos a venda no mercado; 2) tornar a matemática estimulante, fonte de conhecimentos novos, a partir de situações reais e contextuais.

Este texto está dividido em quatro partes, além desta introdução. Na primeira parte, apresentamos uma concepção de ensino de matemática em um cenário social em que se exige do cidadão conhecimentos matemáticos relacionados às situações reais do cotidiano, conceitos estes embasados pelos documentos orientadores curriculares dessa disciplina. Em seguida, apresentamos um breve histórico sobre o surgimento, finalidade e evolução dos códigos de barras, e sua importância no atual mundo globalizado e automatizado. Em sequência, apresentamos a proposta de situação de aprendizagem, contemplando o tema de estudo deste trabalho, composta por cinco etapas, com orientações didáticas relativas a conceitos e procedimentos matemáticos e uso das tecnologias. Por fim, em nos- sas considerações finais, analisamos os possíveis obstáculos que podem surgir durante o seu desenvolvimento, com a finalidade de contribuir para o enriquecimento do ensino da Matemática.

\section{$2 \mathrm{O}$ ensino de matemática e a formação cidadã na era digital}

Com o grande avanço tecnológico, houve mudanças significativas na sociedade, principalmente no mundo do trabalho, no qual os atuais profissionais precisam ser "mais criativos e versáteis, capazes de entender o processo de trabalho como um todo, dotados de autonomia e iniciativa para resolver problemas em equipe e para utilizar diferentes tecnologias e linguagens." (Brasil, 1998, p.27).

A escola entra com um importante papel de proporcionar aos alunos o desenvolvimento de competências e habilidades que garantem a formação do cidadão, frente a esse novo perfil de profissional, levando-os a compreender a importância do uso da tecnologia e de acompanhar sua constante renovação.

Atualmente, é comum a aquisição de produtos tecnológicos pelos alunos, tais como celulares, tablets, notebooks, computadores, onde o acesso à internet se traduz como um bombardeio de informações.

Diante dessa complexa sociedade, onde as informações são produzidas e incorporadas a todo instante, cabe ao professor, no seu papel de mediador no processo de ensino-aprendizagem, desenvolver técnicas e metodologias atrativas que levem à construção do conhecimento, neste trabalho em especial, à construção do conhecimento matemático.

De acordo com os Parâmetros Curriculares Nacionais (1998) “A Matemática caracteriza-se como uma forma de compreender e atuar no mundo e o conhecimento gerado nessa área do saber como um fruto da construção humana na sua interação constante com o contexto natural, social e cultural." (Brasil, 1998, p.24).

Dessa forma, não se pode mais ver a Matemática como sendo apenas uma disciplina que se usa na sala de aula, pronta e acabada, mas sim como uma [...] ciência viva, não apenas no cotidiano dos cidadãos, mas também nas universidades e centros de pesquisas, onde se verifica, hoje, uma 
impressionante produção de novos conhecimentos que, a par de seu valor intrínseco, de natureza lógica, têm sido instrumentos úteis na solução de problemas científicos e tecnológicos da maior importância. (Brasil, 1998, p.24).

As pessoas vivem, hoje, inseridas num "mundo informatizado". Até para tarefas simples, como retirar uma senha em vários estabelecimentos, já se conta com auxílio de uma máquina. Não há dúvidas de que os computadores, atualmente, são instrumentos de grande importância tanto no âmbito cultural como no social e econômico, "mas é no terreno da Matemática que se abrem as mais naturais e promissoras possibilidades de assimilação consciente dos inúmeros recursos que as tecnologias informáticas podem oferecer no ramo da Educação" (São Paulo, 2012, p.27).

Adequar essas tecnologias aos objetivos da aprendizagem é uma ação importante do professor. Propor atividades nas quais os alunos percebam a relação entre os conceitos matemáticos, as tecnologias e a realidade, torna a atividade mais significativa para o aluno, proporcionando também uma conexão com outras áreas do conhecimento.

De acordo com o Currículo de Matemática do Estado de São Paulo (2012) “A caracterização dos conteúdos disciplinares como meio para a formação pessoal coloca em cena a necessidade de sua contextualização, uma vez que uma apresentação escolar sem referências, ou com mínimos elementos de contato com a realidade concreta, dificulta a compreensão dos fins a que se destina" (São Paulo, 2012, p.30).

Muitas vezes, quando se introduz um conceito matemático, é comum os alunos indagarem: Onde vou usar isso? Para que serve a Matemática?

O absentismo por parte dos alunos, nesta disciplina, é maior do que nas outras (Silva; Martins, 2000). Talvez, devido a uma cultura de um passado próximo, onde aprender matemática era decorar fórmulas e procedimentos para resolução de problemas.

Hoje, os profissionais da educação têm que ser flexíveis e reavaliar as práticas pedagógicas adotadas, buscando sempre situações de aprendizagem motivadoras e prazerosas que levem à construção do conhecimento. Tarefa nada fácil diante de tantas inovações tecnológicas.

Após seis décadas do surgimento dos códigos de barras, apenas nos últimos anos esse assunto está sendo tratado como uma situação de aprendizagem na sala de aula. Muitos ainda acreditam que o código de barras serve apenas para ver o preço do produto e não tem ideia da relação entre a matemática e essa grande descoberta.

É fundamental, no entanto, que a valorização da contextualização seja equilibrada com o desenvolvimento de outra competência, igualmente valiosa: a capacidade de abstrair o contexto, de generalizar e, sobretudo, a capacidade de imaginar situações fictícias, que não existem concretamente, ainda que possam vir a ser realizadas (São Paulo, 2012, p.30).

\section{Uma breve história do surgimento e evolução dos códigos de barras}

Atualmente, os "Códigos" fazem parte da nossa vida. Desde o nascimento, ainda na maternidade, temos uma identificação e, daí por diante, os códigos entram em nossas vidas de forma galopante. Temos um Registro de Certidão de Nascimento, Registro de Identidade (RG), Cadastro de Pessoa Física (CPF), Carteira Profissional, Título de Eleitor e outros documentos identificados com números e/ou letras. Além disso, nos supermercados, nas farmácias, nas bancas de revistas, nas livrarias, etc., os produtos são acompanhados de etiquetas com seu código, as agências bancárias têm um númerocódigo, assim como a conta corrente. Moramos em um endereço com Código de Endereçamento Postal (CEP), possuímos telefones, carros, computadores e muitos outros itens que possuem um código de identificação. (Fini, 2009).

Há algumas décadas, em estabelecimentos comerciais, o preço de cada produto era colocado manualmente e, quando vendido, tinha que ser digitado numa máquina pela operadora, um processo lento e sujeito a falhas. Com o "recente progresso das tecnologias de computação e automação, os aparelhos de leitura óptica e os computadores ficaram mais acessíveis, tanto do ponto de vista cultural como do econômico." (Fini, 2009, p.71). Com isso, muitas empresas conseguiram se modernizar e passaram a contar com ferramentas que facilitam o controle dos estoques e a identificação dos produtos.

Segundo a GS1-Brasil "A automação começa com a implantação de equipamentos, e a substituição dos procedimentos e rotinas manuais por informatizados, até chegar à utilização de ferramentas que 
possibilitam um maior controle e uma melhor gestão do negócio, obtendo maior rentabilidade e competitividade." (GS1-Brasil)

De modo geral, os sistemas de identificação utilizam números: "além de serem mais eficientes do que os nomes para armazenar e transmitir dados, os números transpõem a barreira dos idiomas, pois são usados internacionalmente." (Fini, 2009, p.71).

O código de barras é uma forma de representação gráfica que viabiliza a captura automática dos dados por meio de leitura óptica nas operações automatizadas.

Esses dados também são representados pela sequência numérica, escrita no sistema de numeração decimal, que aparece imediatamente abaixo das barras, de forma que o leitor humano também possa ler a identificação.

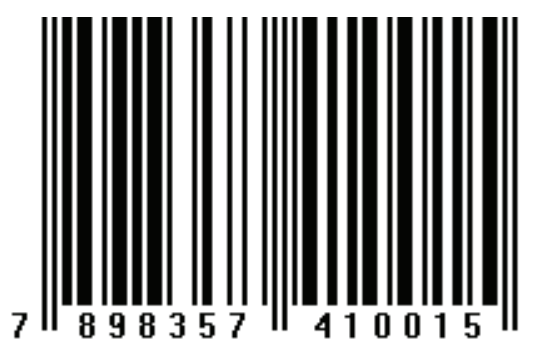

Figura 1: Exemplo de código de barras

Observa-se que a representação é feita geralmente com barras "brancas" e "pretas" de diferentes larguras, as quais, através do leitor óptico e do computador, são "interpretadas" e "decodificadas" em sequências de "zeros" (barras brancas) ou "uns" (barras pretas), graças ao sistema binário para a escrita de qualquer número na usual base 10. (Fini, 2009, p.74).

De acordo com Polcino Milies (2009), as primeiras ideias sobre os modernos códigos de barras surgiram por volta de 1948, graças aos estudantes Bernard Silver (Figura 3) e Norman Joseph Woodland (Figura 2), do Instituto de Tecnologia Drexel, na Filadélfia.

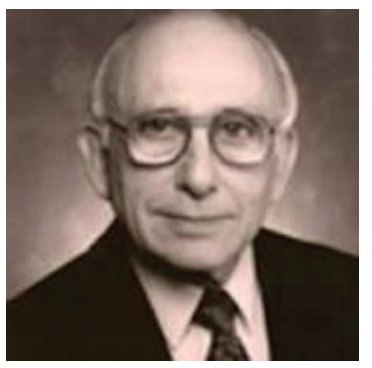

Figura 2: Normam J. Woodland (1921 - 2012)

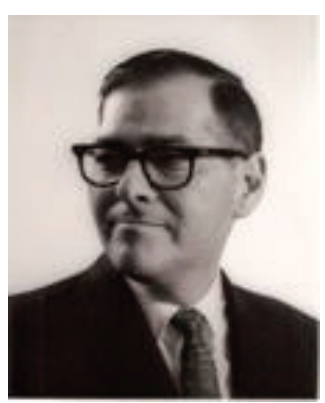

Figura 3: Bernard Silver (1924 - 1963)

Seus resultados iniciais, um sistema de linhas e círculos baseados no código Morse, foi substituído por um padrão de circunferências concêntricas de largura variável (Figura 4). Silver e Woodland registraram uma patente para o seu sistema em 20 de outubro de 1949, porém, a mesma só foi concedida em 1952. Ao dar entrada ao pedido de patentes, eles descreviam seu invento como uma "classificação de artigos através de identificação de padrões".

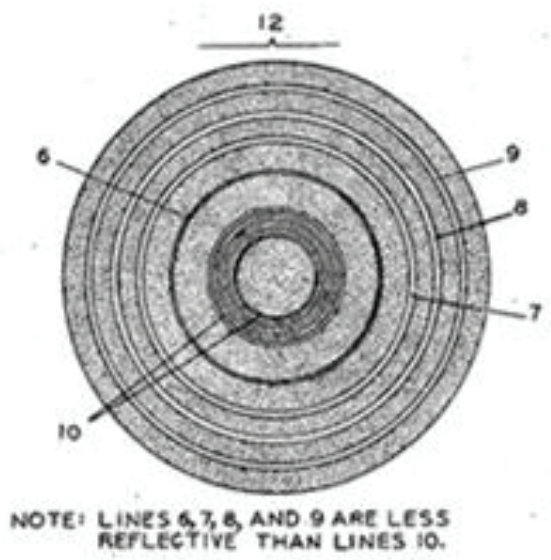

Figura 4: Modelo do primeiro código de barras

Em torno de 1970, uma firma de assessoria, a McKinsey \& Co., junto com a Uniform Grocery Product Code Council, definiu um formato numérico para identificar produtos e pediu a diversas companhias que elaborassem um código adequado. Dentre as companhias contactadas, a que acabou apresentando a proposta vencedora foi a IBM e o autor desse código foi George J. Laurer.

O código proposto, formalmente aceito em maio de 1973, passou a ser conhecido como código UPC (Universal Product Code) e foi adotado nos Estados Unidos e Canadá (Figura 5). Ele consistia de uma sequência de 12 dígitos, traduzidos para barras claras e escuras, seguindo a rigorosos padrões. Existem várias versões sucessivas do UPC, com pequenas modificações. 


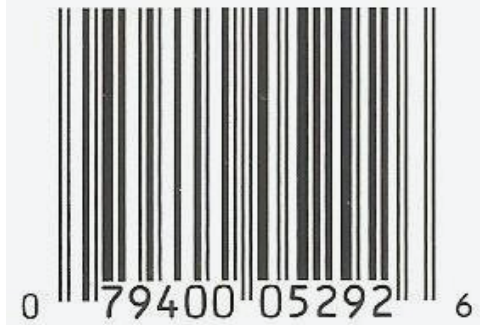

Figura 5: Exemplo de código de barras UPC - A

Posteriormente foi solicitado a Laurer que ampliasse o código, para permitir uma maior difusão do sistema, de modo a identificar também o país de origem de cada produto classificado. Baseado no UPC-A, ele acabou criando um novo código, com 13 dígitos (Figura 6), que foi adotado em dezembro de 1976 com o nome EAN (European Article Numbering system). Alguns países adotam este mesmo sistema, dando-lhe outro nome. Por exemplo, no Japão o sistema é conhecido como JAN (Japanese Article Numbering system).

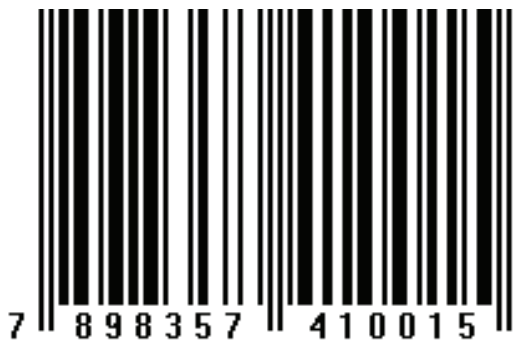

Figura 6: Exemplo de código de barras EAN-13

Desde 1974, quando foi escaneado o primeiro código de barras nos Estados Unidos, as mudanças no universo do varejo e da indústria foram constantes e aceleradas. A automação trouxe efeitos imediatos na cadeia de suprimentos e principalmente na vida dos consumidores. Além de fornecer números exclusivos de identificação, os códigos padronizados também proporcionam informações adicionais, tais como: data de validade, números de série e números de lote.

Existe, atualmente no mercado, uma expectativa para que seja possível identificar os produtos comercializados no varejo, com a inclusão de dezenas de informações relacionadas a cada produto e com a isenção do pagamento de taxas e filiações para órgãos internacionais.

Com essa nova tendência mundial, "o código de barras bidimensional QR-code (quick res- ponse code)", é possível especificar até 7.079 caracteres numéricos, 4.296 caracteres alfa numéricos, 2.953 caracteres binários e até 1.817 caracteres Kanji/Kana (Japoneses). Além das infinitas aplicações utilizando o Código de Barras Bidimensional QR-code (Figura 7), também é possível efetuar a leitura com seu aparelho celular, sem a utilização de scanners e leitores especializados.

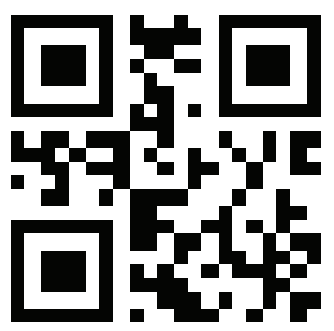

Figura 7: Exemplo de código bidimensional (QR - code)

\section{Uma proposta de situação de apren- dizagem de matemática contextualiza- da com os códigos de barras}

Nesta seção, apresentamos uma proposta de atividade didática relacionada aos códigos de barra, planejada para a 7ª Série/8o Ano do Ensino Fundamental, com a intenção de contribuir com estudos de aplicações de conceitos matemáticos importantes ao desenvolvimento da aprendizagem escolar dos estudantes. A situação de aprendizagem foi estruturada em 5 etapas, a saber: Etapa 1) Reconhecimento dos códigos de barras; Etapa 2) Estrutura dos códigos de barras; Etapa 3) Cálculo do dígito verificador; Etapa 4) Como escrever com barras; Etapa 5) Criando um código de barras. Cada uma destas etapas é apresentada e explicada na sequência deste texto.

Antes da apresentação das atividades elaboradas nesta situação de aprendizagem, expomos a seguir os pré-requisitos essenciais a sua execução:

- Saber realizar operações com números naturais de modo significativo (adição, subtração, multiplicação, divisão, potenciação).

- Compreender informações transmitidas em tabelas.

- Compreender o funcionamento de sistemas decimais e não decimais de numeração, em especial, a base binária. 
Sugerimos os seguintes materiais e equipamentos para serem utilizados na execução da proposta:

- Materiais de uso diário como: caderno, lápis, canetas, borracha - para os registros durante o desenvolvimento da atividade.

- Recortes de vários códigos de barras - objeto de análise da atividade.

- Computador/Sala de Informática: viabilizar com eficácia o processo de codificação e decodificação.

- Fichas com representação de barras - para facilitar na resolução dos problemas.

O uso do computador, nessa atividade, tem como objetivo substituir o moroso trabalho manual na realização das mudanças da base de um número escrito no sistema de numeração decimal para o binário, e vice-versa. Para esta função foi feito um programa bastante simples, por um colaborador. Cujo comando é:

Digitar 1: para transformar número decimal em binário

Digitar 2: para transformar número binário em decimal

Pela simplicidade do programa, talvez na própria escola, dentre colegas e alunos (com conhecimento em informática), o professor possa encontrar um colaborador.

É importante que o professor tenha conhecimentos prévios sobre os conceitos matemáticos envolvidos na execução da proposta. O tempo para cada atividade depende do envolvimento e empenho dos alunos. Em cada etapa é importante que o professor auxilie e incentive seus alunos na realização dos registros dos resultados obtidos, para análise posterior.

\subsection{Etapa 1: Reconhecimento dos códigos de barras}

Este momento é caracterizado pela apresentação do assunto aos alunos e pelos questionamentos iniciais feitos pelo professor. O professor poderá introduzir o tema dialogando com os alunos.

- Argumentar sobre os códigos de barras: Conhecem? Onde encontrar? Todo produto tem? Para que serve? - Fazendo uma avaliação diagnóstica sobre o conhecimento dos alunos em relação ao tema.

- Como tarefa, pedir aos alunos que tragam de casa diversos tipos de embalagens que contenham códigos de barras.

\subsection{Etapa 2: Estrutura dos códigos de barras}

Esta etapa é dividida em duas partes, A e B: a parte A é caracterizada pelo reconhecimento das semelhanças e diferenças que os alunos atribuem às sequências numéricas dos códigos de barras e, na parte B, é apresentada e discutida pelo professor a estrutura EAN-13 (Figura 8), padrão dos códigos de barras utilizado atualmente.

\subsubsection{Parte A: Propor aos alunos que for- mem grupos e apresentem os materiais que trouxeram de casa}

- Pedir que observem os códigos fazendo comparações entre eles, verificando as diferenças e/ou semelhanças encontradas. (Espera-se que os alunos identifiquem: sequências iguais (pelo menos em partes), quantidades iguais de dígitos em cada código, etc.)

- Compartilhar os resultados de cada grupo.

Nesse momento, é importante a intervenção do professor, abordando de forma sucinta os aspectos históricos dos códigos de barras: quando surgiu, com qual finalidade, sua evolução, seus benefícios para a sociedade atual. Deve-se também, falar sobre a estrutura dos códigos de barras, mais precisamente os três primeiros dígitos, os quais informam o país de origem do produto.

Atualmente, é muito comum encontrar no comércio produtos importados, principalmente artigos escolares. É interessante, se possível, que o professor providencie alguns exemplos de códigos de barras de produtos importados, para que os alunos observem de fato as diferenças, caso ninguém tenha trazido.

\subsubsection{Parte B: Apresentação da estrutura do código de barras - EAN-13, padrão adota- do pelo Brasil}

No sentido de facilitar, o professor pode apresentar aos alunos um esquema com a estrutura do código de barras - EAN-13, conforme ilustrado na figura 8 :

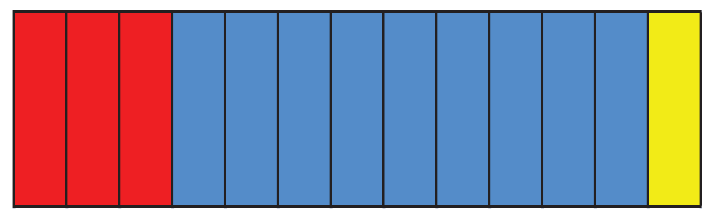

Figura 8: Estrutura de um Código de barras Padrão EAN-13 
Na figura 8, as barras correspondem aos dígitos que formam o código, onde:

- os 3 primeiros dígitos (barras vermelhas): representam o código do país de origem (no caso do Brasil - 789).

- os próximos 9 dígitos (barras azuis): contém as informações que identificam a empresa e o produto.

- o último dígito (barra amarela): é o algarismo de controle, obtido através de um algoritmo (regras) que envolve os doze dígitos anteriores.

Deve-se destacar, também, seu principal objetivo: identificar, com segurança, um objeto ou um artigo, de acordo com o país de origem, a empresa que o produz e o tipo de produto.

\subsection{Etapa 3: Cálculo do dígito verificador}

Para esta etapa, o professor pode manter os grupos formados anteriormente. Como se trata de alunos da $7^{\text {a }}$ série/8o ano, para calcular o dígito verificador, a sugestão é apresentar o algoritmo de forma bastante simples através de um exemplo.

Deve-se enfatizar que o dígito verificador é o resultado de um algoritmo (algoritmo é uma sequência de instruções que podem ser executadas mecanicamente, por uma pessoa ou máquina - computador) que envolve os dígitos anteriores, e não contém informações sobre o produto. Dependendo do padrão adotado, o algoritmo pode ser diferente.

\subsubsection{Parte A: Analisando um exemplo}

O professor apresenta e discute um exemplo de como obter o dígito verificador de um código de barras.

Como exemplo, vamos analisar o código de barras do Caderno do Professor de Matemática (Figura 9).

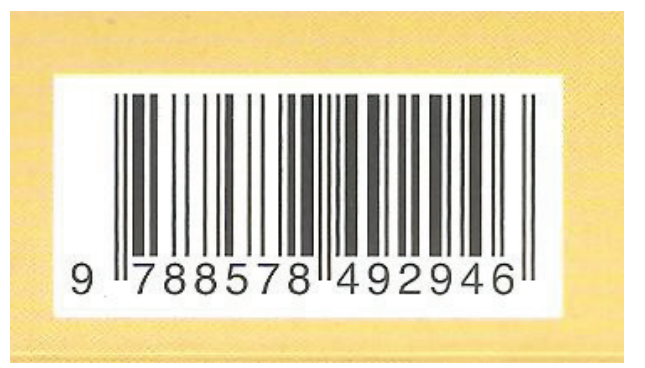

Figura 9: Código de barras do Caderno do Professor de Matemática - Ensino Fundamental - 7a série. Volume 2 (SEE, 2009)
O algoritmo utilizado para obtermos o dígito verificador é apresentado abaixo:

19) Da esquerda para a direita, escreva 1 e 3, alternadamente, abaixo de cada um dos 12 primeiros dígitos.

\begin{tabular}{|l|l|l|l|l|l|l|l|l|l|l|l|}
\hline 9 & 7 & 8 & 8 & 5 & 7 & 8 & 4 & 9 & 2 & 9 & 4 \\
\hline 1 & 3 & 1 & 3 & 1 & 3 & 1 & 3 & 1 & 3 & 1 & 3 \\
\hline
\end{tabular}

$\left.\mathbf{2}^{\mathbf{a}}\right)$ Multiplique cada dígito do código pelo dígito colocado imediatamente abaixo dele e some todos os produtos obtidos.

\begin{tabular}{|c|c|c|c|c|c|c|c|c|c|c|c|}
\hline 9 & 7 & 8 & 8 & 5 & 7 & 8 & 4 & 9 & 2 & 9 & 4 \\
\hline $\mathrm{x}$ & $\mathrm{x}$ & $\mathrm{x}$ & $\mathrm{x}$ & $\mathrm{x}$ & $\mathrm{x}$ & $\mathrm{x}$ & $\mathrm{x}$ & $\mathrm{x}$ & $\mathrm{x}$ & $\mathrm{x}$ & $\mathrm{x}$ \\
\hline 1 & 3 & 1 & 3 & 1 & 3 & 1 & 3 & 1 & 3 & 1 & 3 \\
\hline
\end{tabular}

Assim obtém-se a soma: $9+21+8+24+5+21+8+12+9+6+9+12=144$.

$3^{\text {o) }}$ Agora, o dígito verificador é o número que, adicionado à soma obtida, a transforma num múltiplo de 10. Dessa forma, tem-se que o dígito verificador desse produto é o número 6, o que facilmente é certificado pela Figura 9.

\subsubsection{Parte B: Realização da atividade pelos alunos}

Após o exemplo, propor aos grupos que realizem esse procedimento com alguns dos seus códigos, sempre registrando os resultados obtidos. O professor deve acompanhar a realização dessa atividade para auxiliar os alunos, caso houver dúvidas.

Podemos também sugerir como tarefa, dependendo do interesse dos alunos, uma pesquisa sobre outros códigos que possuem dígito verificador, como é o caso do RG e CPF. Existem vários sites na internet que mostram com clareza os algoritmos utilizados.

Observações:

-Pode-se usar como exemplo, um dos códigos trazidos pelos alunos.

-Quando esta atividade for desenvolvida com os alunos do Ensino Médio, esse algoritmo pode ser apresentado usando os conceitos de congruência - Aritmética Modular.

\subsection{Etapa 4: Como escrever com barras}

Inicialmente, recordamos com os alunos um pouco da história dos códigos de barras e apresentamos a importância da evolução dos recursos tecnológicos para o crescimento econômico mundial, tais como o leitor óptico e computado- 
res, além de ressaltar também a linguagem dos computadores - base binária (bits). Esse assunto é abordado com bastante clareza no caderno do $1^{\circ}$ bimestre das Escolas Estaduais, e serve como referência para melhor entendimento do assunto.

Após esta apresentação inicial, começamos a desenvolver o raciocínio da atividade através de um exemplo apresentado pelo professor. Para facilitar o desenvolvimento desta atividade, a barra branca será representada por "zero" e a barra preta, por "um".

Esta atividade tem por objetivo, recordar a escrita na base binária, bem como a transformação para a base 10 e vice-versa.

\subsubsection{Parte A: Analisando exemplos Exemplo 1}

Transformar a representação gráfica em um número na base 10 - decodificação.

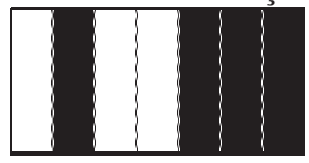

$1^{0}$ passo: Identificar as barras brancas com o dígito "zero" e as barras pretas, com "um".

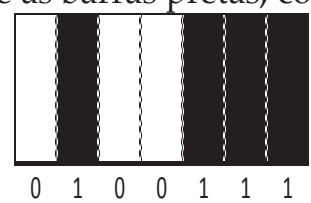

Então, as barras estão representando o número 0100111 na base binária. Para facilitar, pode-se usar a seguinte notação: $(0100111)_{2}$

$2^{\mathbf{0}}$ passo: Transformar o número (0100111) $)_{2}$ na base decimal. Para a conversão, utilizamos as potências de 2:

$0100111=\left(0 \times 2^{6}\right)+\left(1 \times 2^{5}\right)+\left(0 \times 2^{4}\right)+$ $\left(0 x 2^{3}\right)+\left(1 \times 2^{2}\right)+\left(1 \times 2^{1}\right)+\left(1 \times 2^{0}\right)=0+32+$ $0+0+4+2+1=39$, que será assim representado: $(39)_{10}$.

\section{Exemplo 2}

Transformar o número $(100)_{10}$ na base binária e fazer sua codificação por barras.

$1^{0}$ passo: Transformar o número $(100)_{10}$ na base binária. Um procedimento simples é efetuar divisões sucessivas por 2, e considerar os "restos" de cada divisão para o representação do número na nova base. A tabela abaixo apresenta os resultados para este exemplo.

\begin{tabular}{|c|c|}
\hline 口 $2=50$ & o \\
\hline $50: 2=25$ & esco \\
\hline 25 : & to \\
\hline $112: 2$ & sto \\
\hline 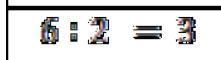 & esto \\
\hline 要 $: 2=1$ & resto 1 \\
\hline $11: 9$ & ssto 1 \\
\hline
\end{tabular}

O processo termina quando o novo quociente for zero.

Na nova base o número é formado pelos restos obtidos, e a leitura é feita de baixo para cima. Logo, temos o seguinte código formado:

$(100)_{10}=(1100100)_{2}$

$2^{\mathrm{a}}$ passo: Escrever com barras o número encontrado. O aluno deverá fazer a correspondência entre os números e as barras, pintando de preto aquelas que representam o número 1.

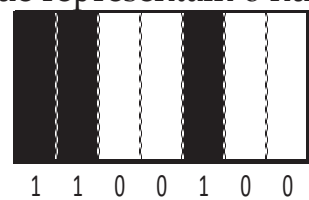

Finalmente, a codificação está pronta.

\subsubsection{Parte B: Realização da atividade pelos alunos}

O professor deverá elaborar uma folha com alguns exercícios, conforme os exemplos acima, para que os alunos possam praticar esses procedimentos (assuntos previstos para serem abordados na $5^{\mathrm{a}}$ e $6^{\underline{a}}$ séries), uma oportunidade para os alunos colorirem as barras pretas, uma atividade prazerosa para eles dessa fase.

É importante que os alunos percebam que esse processo de forma manual é muito trabalhoso e inviável para identificar grandes quantidades de produtos ou serviços.

\subsection{Etapa 5: Criando um código de barras}

O objetivo desta atividade é despertar no aluno a capacidade de criar, de inovar, e principalmente, de verificar que os conceitos matemáticos relacionados a elaboração dos códigos de barras são de grande importância para o desenvolvimento econômico do mundo moderno.

Propomos que esta atividade seja desenvolvida na sala de informática, com uso do computador. Caso o professor não tenha esse recurso disponível, poderá também usar calculadoras para auxiliar no desenvolvimento desta atividade. 


\subsubsection{Parte A: Propor aos alunos a criação} de um código de barras fictício, utilizando os conhecimentos adquiridos nas atividades anteriores

$1^{\mathbf{0}}$ passo: Cada grupo deverá pensar num tema para a construção do código e discutir sobre qual a melhor estrutura, isto é, verificar se o tamanho do código de barras escolhido é adequado para receber todas as informações que se deseja. E, através de tentativas, fazer as adaptações necessárias. Cabe ao professor acompanhar e orientar nessas tomadas de decisões.

A título de sugestão, apresentamos a seguir um exemplo de tema para discussão e algumas das possíveis dúvidas que poderão aparecer no decorrer dessa atividade.

Consideremos o tema: "Identificação dos alunos" de uma Escola de Ensino Fundamental. Suponha que, nesta escola, em cada um dos períodos, tenha apenas uma classe por série.

10) Descrever as informação que serão representadas no código.

Escola: 25

Turnos: manhã:1 e tarde:3

Séries: $5^{\underline{a}}, 6^{\underline{a}}, 7^{\underline{a}}$ e $8^{\underline{a}}$

Número de chamada: 1 a 35

$2^{\mathbf{0}}$ ) Esquematizando a estrutura

\begin{tabular}{|c|c|c|c|}
\hline Escola & Turno & Série & $\begin{array}{c}\text { Número } \\
\text { da } \\
\text { chamada }\end{array}$ \\
\hline 25 & 1 & 5 & 1 \\
& 3 & 6 & 2 \\
& & 7 & $\cdot$ \\
& & 8 & 35 \\
\hline
\end{tabular}

Agora, para a codificação, é necessário que se escreva os dados na base binária.

$2^{\mathbf{o}}$ passo: É preciso verificar quantos bits são necessários para representar cada número, para padronização das barras. Deve-se analisar, dentro de cada informação, o maior número escrito na base decimal, para definir esse padrão. Nesta parte, o computador pode ser utilizado a fim de otimizar o tempo, facilitando assim as tomadas de decisões. Essa operação é mostrada com clareza nos exemplos abaixo.

No caso da identificação da escola, o número é 25:

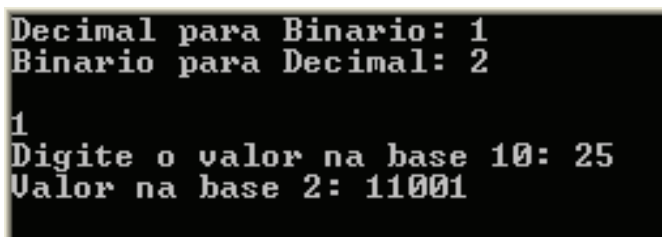

Percebemos pelo resultado obtido que é preciso utilizar 5 bits, ou seja, 5 barras para a representação da escola. Dessa forma, no código a ser criado, os primeiros cinco dígitos serão utilizado para indicar a escola.

Realizamos agora as mesmas operações para determinar quantos bits serão necessários para indicar os turnos:

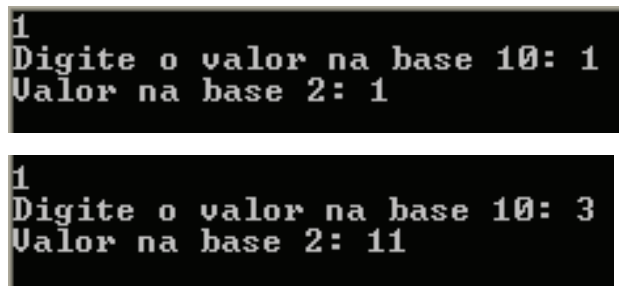

Consideramos importante que os alunos percebam que, para padronizar as barras, serão necessários 2 bits para descrever os turnos. E a representação de cada turno ficaria assim:

Manhã: $(1)_{10}=(01)_{2}$

Tarde: $(3)_{10}=(11)_{2}$

Da mesma forma, obtém-se:

- para as séries: $(5)_{10}=(101)_{2}$ e $(8)_{10}=(1000)_{2}$. Serão necessários 4 bits.

- para os números da chamada: $(1)_{10}=(1)_{2}$ e $(35)_{10}=(100011)_{2}$

Assim, para essa informação deve-se reservar 6 bits.

Então, a estrutura ficaria assim:

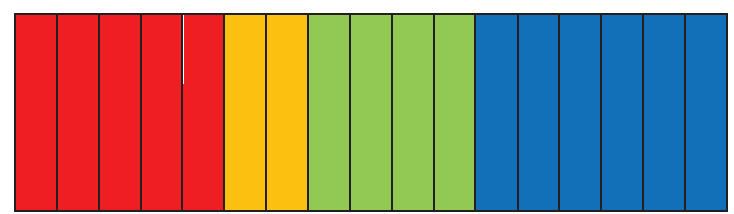

onde as barras:

- Vermelhas: representam a escola -5 bits

- Laranjas: representam o turno - 2 bits

- Verdes: representam a série -4 bits

- Azuis: representam o número de chamada -6 bits

Concluímos que, neste exemplo utilizado para identificar todos os alunos dessa escola (utilizando a hipótese de apenas uma turma de cada série por período), é preciso que o tamanho do código seja de 17 bits, no mínimo. 


\subsubsection{Parte B: Codificando e Decodificando}

De posse das informações e conhecimentos necessários a construção de um código de barras para representar os alunos, agora aplicaremos estes conhecimentos para a representação desses alunos.

Passo 1: Codificando um aluno que estuda nessa escola, na $7^{\text {a }}$ série do período da tarde, cujo número de chamada é 6 .

Dados para a identificação: $25-3-7-6(\mathrm{Ob}-$ serva-se que a ordem é importante).

Novamente, fazendo uso do recurso tecnológico (computador), o qual efetua as conversões dos números escritos na base 10 para a base 2 , podemos obter as representações binárias de cada informação que constituirão o código.
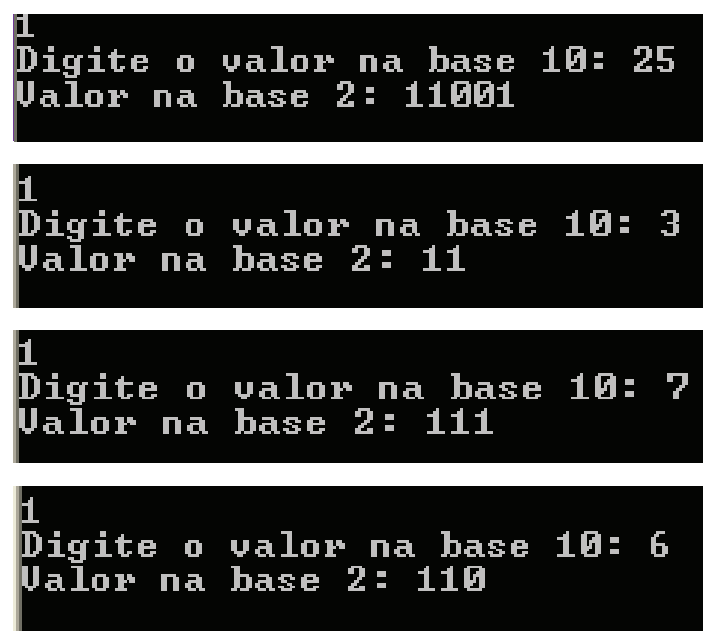

Daí, obtém-se a seguinte identificação do aluno: 11001- 11- 0111- 000110, cujo código de barras é:

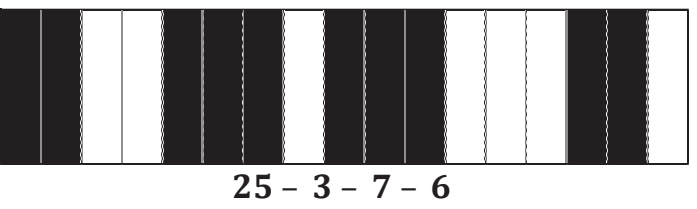

Passo 2: Decodificando - Cada aluno vai registrar seu código (em barras) e entregará ao professor, que posteriormente devolverá (de forma aleatória) para que cada um faça a decodificação e identifique o colega.

Voltando ao exemplo anterior, o aluno terá que fazer o seguinte procedimento: A folha recebida teria apenas o código de barras.

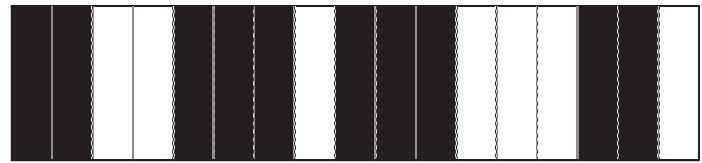

Primeiramente, o aluno deve identificar cada barra branca por "zero" e cada barra preta por "um".

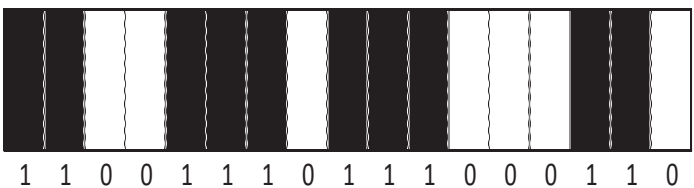

Agora, segundo o padrão da estrutura do código em questão, é possível separar os dígitos:

11001 - 11 - 0111 - 000110

Com o uso do computador, obtemos:
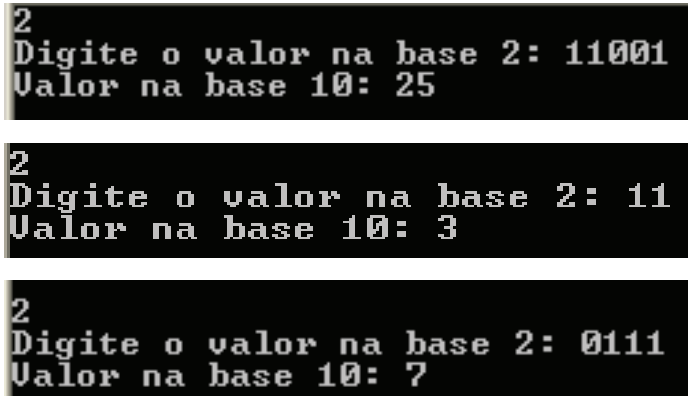

Jalor na base 10: ?

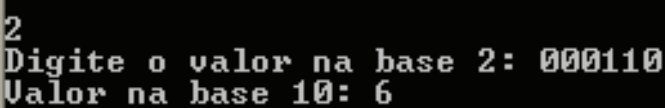

Assim, o código na versão decimal é: 25 - 3 $7-6$, o que nos garante que o aluno aí representado, é um aluno da escola, estuda no período da tarde, na $7^{\text {a }}$ série, matriculado com o número 6 da chamada.

Depois de concluída essa atividade, é interessante que o professor verifique os registros dos grupos e analise os códigos criados por cada um, e proponha algumas situações problemas, tais como (ainda considerando o exemplo analisado):

- Se forem matriculados mais alunos numa determinada série, ainda assim seria possível usar o mesmo código de barras sem alterar a sua estrutura? A partir de que quantidade de alunos essa estrutura teria que ser mudada?

- Se a escola tivesse mais que uma turma por série, num mesmo período, por exemplo, 5aㅡ $\mathrm{A}$ $5^{\mathrm{a}} \mathrm{B}$, como representar?

- É possível justapor ao código um dígito verificador?

Lembramos que o professor pode se surpreender, e que estes questionamentos sejam feitos pelos próprios alunos durante a elaboração da 
atividade. Pode ocorrer, também, que algum grupo tenha usado mais bits do que o necessário para a representação do código. Neste caso, pode-se instigar o grupo a repensar na estruturação do código com a finalidade de otimizar o espaço de armazenamento do computador, caso realmente fosse aplicado.

Para finalizar, é importante que seja apresentado ao aluno, a forma real da representação dos números para a formação dos códigos. De acordo com o Currículo do Estado de São Paulo (2012, p.33): "A realidade costuma ser muito complexa para uma apreensão imediata; as abstrações são simplificações que representam um afastamento provisório da realidade, com a intenção explícita de melhor compreendê-la."

\section{Considerações finais}

Não há dúvidas de que estamos inseridos em um mundo no qual o conhecimento é usado de forma intensiva e o diferencial está na qualidade da educação proporcionada aos alunos em idade escolar.

Assim, ressaltamos a importante função dos professores, proporcionando aos alunos situações de aprendizagem que desenvolvam competências e habilidades necessárias para a construção do próprio conhecimento, buscando a formação de cidadãos autônomos, críticos e conscientes do seu papel na sociedade.

Por meio deste trabalho, foi proposta uma situação de aprendizagem caracterizada pela compreensão e criação de um código de barras, em que buscamos articular o real e o fictício, proporcionando um ambiente investigativo e criativo onde será possível fazer conexões entre diversos conceitos matemáticos, suas diferentes formas de pensamento com outras áreas do saber e com as aplicações na atualidade.

Esta atividade proposta abre um leque de possibilidades para a construção do conhecimento matemático, o que constitui ferramenta fundamental para a articulação entre a teoria e a prática, o global e o local, o abstrato e o real. (São Paulo, 2012). Também entendemos que esta iniciativa ajuda a incentivar a leitura e a escrita matemática, além de proporcionar uma maior participação do aluno nas aulas desta disciplina e de desenvolver o espírito crítico e inovador, melhorando a interação professor/aluno dentro de um ambiente de aprendizagem mútua.
Esperamos que esta sugestão de atividades seja útil para outros professores e que venha contribuir para a melhoria da qualidade do ensino da matemática.

\section{Nota do autor}

Este artigo foi elaborado a partir da dissertação de mestrado "A Matemática dos Códigos de Barras", sob a orientação do Prof. Dr. Jéfferson Luiz Rocha Bastos, do Programa de Mestrado em Matemática em Rede Nacional, na Universidade Estadual Paulista "Júlio de Mesquita Filho", Campus de São José do Rio Preto.

\section{Referências}

BRASIL, Secretaria de Educação Fundamental. Parâmetros curriculares nacionais: Matemática. Secretaria de Educação Fundamental. Brasília: MEC /SEF, 1998.

FINI, Maria Inês. Controle dos Códigos de Identificação. Revista do Professor - Atualidades, SEESP, Edição nํ2, p. 70 - 75, 2009.

GS1 BRASIL (Associação Brasileira de Automação). Disponível em: http:www.gs1br.org/. Acesso em 15/01/2013.

POLCINO MILIES, C. A matemática dos códigos de barras. Programa de Iniciação Científica da OBMEP. Rio de Janeiro: OBMEP, 2009, v., p. 131-179.

SÃO PAULO (Estado) Secretaria da Educação. Currículo do Estado de São Paulo: Matemática e suas tecnologias / Secretaria da Educação; coordenação geral, Maria Inês Fini; coordenação de área, Nilson José Machado. - 1. ed. atual. - São Paulo: SE, 2012.

SILVA, Anabela; MARTINS, Suzana. Falar de matemática hoje é ... (2000). Millenium, n. 20, outubro de 2000. Disponível em: http://www.ipv.pt/millenium/20_ect5.htm. Acesso em: 15 jan. 2013. 